\title{
DETECÇÃO DE SEQUÊNCIAS PROTEICAS IMUNOGÊNICAS DA NEURAMINIDASE DE Porphyromonas gingivalis ATCC 33277: AVALIAÇÃO IN SILICO COM ALELOS HLA-DQ
}

\author{
Talita Lima Lula ${ }^{1}$; Isaac Suzart Gomes Filho² ${ }^{2}$ Ellen Karla Nobre dos Santos \\ Lima $^{3}$; Márcia Tosta Xavier ${ }^{4}$; Soraya Castro Trindade ${ }^{5}$. \\ 1. Bolsista PIBIC/CNPq, Graduanda em Odontologia, Universidade Estadual de Feira de Santana, e-mail: \\ talitalima.o@hotmail.com \\ 2. Orientador, Departamento de Saúde, Universidade Estadual de Feira de Santana, e-mail: isuzart@gmail.com \\ 3. Participante do projeto, Programa de Pós-Graduação em Imunologia, Universidade Federal da Bahia, e-mail: \\ ellenobre@hotmail.com \\ 4. Participante do projeto, Escola Bahiana de Medicina e Saúde Pública, e-mail: tostamarcia@gmail.com \\ 5. Co-orientadora, Departamento de Saúde, Universidade Estadual de Feira de Santana, e-mail: \\ soraya.castrotrindade@gmail.com
}

PALAVRAS-CHAVE: periodontite; neuraminidase; Porphyromonas gingivalis.

\section{INTRODUÇÃO}

A periodontite é uma doença infecciosa de caráter inflamatório, que acomete os tecidos de suporte do dente, podendo levar à reabsorção de osso alveolar, destruição de fibras colágenas e, por fim, perda dentária (LINDHE, 1999). O fator etiológico primário da periodontite constitui-se na presença de microrganismos patogênicos, como Porphyromonas gingivalis, no biofilme dentário (SOCRANSKY \& HAFFAJJE, 2005).

$P$. gingivalis é um bacilo gram-negativo, anaeróbio estrito, imóvel, intensamente proteolítico e forma colônias marrons ou negras em ágar sangue. É um indutor de inflamação, reconhecido como um dos principais patógenos na periodontite crônica (MAYER et al., 2013).

Considerando que os patógenos desenvolvem mecanismos específicos de interação com seus hospedeiros (ALBERTS et al., 2010), o estudo de moléculas sintetizadas por $P$. gingivalis que contribuam para o desenvolvimento da doença periodontal (TEUGHELS et al., 2011) torna-se relevante. As neuraminidases são proteínas sintetizadas por microrganismos patogênicos, incluindo $P$. gingivalis, e são consideradas fatores de virulência, contribuindo para sua capacidade de induzir a doença periodontal (LI et al., 2012).

A maioria dos linfócitos $\mathrm{T}$ reconhece, como epítopos, peptídeos lineares curtos, pois seus receptores de antígenos (TCR) são específicos para antígenos apresentados por moléculas do MHC presentes na superfície das células apresentadoras de antígeno (APC) e tais moléculas se ligam a peptídeos. Os linfócitos $\mathrm{T} \mathrm{CD}^{+}$reconhecem peptídeos provenientes de proteínas extracelulares, apresentados pelas moléculas MHC de classe II (ABBAS et al., 2011).

Nos seres humanos, os genes que codificam o MHC localizam-se no braço curto do cromossoma 6. O HLA (MHC humano) de classe II possui três loci de genes, denominados HLA-DP, HLA-DQ e HLA-DR. Cada lócus contém vários genes separados denominados $\mathrm{A}$ ou $\mathrm{B}$, que codificam as cadeias $\alpha$ ou $\beta$, respectivamente. A nomenclatura do alelo HLA considera o enorme polimorfismo (variação entre indivíduos) identificado por métodos sorológicos e moleculares (ABBAS et al., 2011).

As análises in silico são ferramentas atuais de compreensão de modelos biológicos sem as desvantagens inerentes à utilização de organismos vivos, como possibilidade de contaminação, custo, além das questões éticas. Nesse contexto, o presente trabalho objetivou identificar in silico epítopos candidatos na sequência 
proteica da neuraminidase de $P$. gingivalis ATCC33277, na indução da resposta imune; utilizando, para a análise, alelos HLA-DQ observados na população em estudo.

A identificação de epítopos peptídicos imunogênicos com afinidade para o HLA antecede a síntese das sequências peptídicas para utilização em experimentos com cultivo celular para a compreensão do papel das neuraminidases na patogênese da periodontite crônica, bem como para a sua posterior utilização em ensaios imunoenzimáticos que auxiliem no diagnóstico da doença.

\section{MATERIAL E MÉTODOS OU METODOLOGIA}

A identificação de peptídeos com potencial imunogênico foi realizada por bioinformática, utilizando programa disponível online (YANG \& YU, 2009), a exemplo do estudo realizado por Bittner-Eddy et al. (2013). A sequência da proteína Neuraminidase de $P$. gingivalis ATCC 33277 foi adquirida no banco de dados do NCBI (National Center for Biotechnology Information) e analisada para a predição de peptídeos que se liguem a receptores MHCII humanos (HLA-DQ) e induzam uma resposta imune em cultura de células humanas. Para a predição, foi utilizada a ferramenta MHC-II Binding Predictions (http://tools.immuneepitope.org/mhcii/) do IEDB (Immune Epitope Database) (YANG \& YU, 2009; VITA et al., 2010). Após a predição, os peptídeos com menor rank percentual foram selecionados para síntese química e para, posterior, avaliação in vitro da capacidade de induzir resposta em células T CD4 ${ }^{+}$.

As sequências peptídicas obtidas foram analisadas para identificação da região proteica utilizando as anotações publicadas no Protein Database do NCBI (BAG34127). A ferramenta Epitope Cluster Analysis (http://tools.iedb.org/cluster/) foi utilizada para agrupar as sequências peptídicas e observar se havia semelhança entre elas. As sequências peptídicas foram comparadas àquelas depositadas no banco de dados IEDB, buscando por similaridade por BLAST (Basic Local Alignment Search Tool).

\section{RESULTADOS E/OU DISCUSSÃO (ou Análise e discussão dos resultados)}

A predição resultou em 6 sequências peptídicas compostas por 15 resíduos de aminoácidos (15-mer). Dentre os peptídeos imunogênicos putativos obtidos, 3 estão no domínio BNR (Bacterial Neuraminidase Repeat). Desses, 1 peptídeo (N3) inclui sítio catalítico da enzima (QUADRO 1).

Não houve formação de grupos de sequências por similaridade (Identity Threshold $90 \%$ ), confirmando serem sequências diferentes entre si. Não houve similaridade com as sequências depositadas no IEDB (Exact Matches / 100\%), indicando o ineditismo das sequências obtidas.

A análise in silico possibilitou a seleção dos peptídeos preditos antes de serem sintetizados. Após a síntese química, os peptídeos imunogênicos integrarão estudos da resposta imune do hospedeiro diante do desafio por $P$. gingivalis na periodontite crônica.

Com este estudo, obteve-se peptídeos com potencial imunogênico que serão sintetizados e utilizados para determinar o perfil de resposta imune de indivíduos com periodontite crônica diante do fator de virulência estudado, favorecendo o entendimento da doença na busca do seu controle e diagnóstico por marcadores biológicos. 


\begin{tabular}{|c|c|c|c|c|c|c|c|c|}
\hline \multirow[b]{2}{*}{ Proteína } & \multirow[b]{2}{*}{$\begin{array}{c}\text { Alelo HLA } \\
\text { (Haplótipo) }\end{array}$} & \multirow[b]{2}{*}{ Código } & \multirow[b]{2}{*}{ Peptídeo } & \multirow[b]{2}{*}{ Início } & \multirow[b]{2}{*}{ Fim } & \multicolumn{3}{|c|}{ Protein Database (NCBI) ${ }^{*}$} \\
\hline & & & & & & $\begin{array}{l}\text { Sialidase } \\
(182-517)\end{array}$ & $\begin{array}{c}\text { Domínio } \\
\text { BNR }^{\star *} \\
(204-500)\end{array}$ & $\begin{array}{c}\text { Sítio } \\
\text { catalítico / } \\
\text { ativo } \\
\text { (Resíduo)\# }\end{array}$ \\
\hline \multirow{6}{*}{$\begin{array}{l}\text { Neuraminidase } \\
\text { (526 aa) }\end{array}$} & DQA1*05:01/DQB1*03:01 & N1 & $\begin{array}{c}\text { LMIFVG } \\
\text { GVGLW } \\
\text { QSTP }\end{array}$ & 268 & 282 & $x$ & $x$ & \\
\hline & DQA1*05:01/DQB1*03:01 & N2 & $\begin{array}{c}\text { RTTALS } \\
\text { ADSVAG } \\
\text { RCF }\end{array}$ & 116 & 130 & & & \\
\hline & DQA1*05:01/DQB1*02:01 & N3 & $\begin{array}{c}\text { DGTIGY } \\
\text { FVEEDD } \\
\text { EIS }\end{array}$ & 496 & 510 & $x$ & $x$ & 504 \\
\hline & DQA1*05:01/DQB1*02:01 & N4 & $\begin{array}{c}\text { SLVFIRF } \\
\text { VLDDLF } \\
\text { DA }\end{array}$ & 510 & 524 & $x$ & & \\
\hline & DQA1*01:02/DQB1*06:02 & N5 & $\begin{array}{c}\text { VVFCCL } \\
\text { MAMMH } \\
\text { LSGQ }\end{array}$ & 17 & 31 & & & \\
\hline & DQA1*01:02/DQB1*06:02 & N6 & $\begin{array}{c}\text { LKTANG } \\
\text { TLIAMAD } \\
\text { RR }\end{array}$ & 199 & 213 & $x$ & $x$ & \\
\hline
\end{tabular}

Quadro 1. Sequências peptídicas de Neuraminidase. Início e fim correspondem à posição na sequência proteica.

*Acesso Protein Database BAG34127.1

**Domínio BNR (Bacterial Neuraminidase Repeat)

\#Resíduos 194, 219, 382, 398, 460, 488 e 504.

\section{CONSIDERAÇÕES FINAIS}

A predição de peptídeos imunogênicos por bioinformática é uma ferramenta útil para estudos de imunogenicidade do patógeno. A análise in silico detalhada possibilitou a seleção dos peptídeos que, após a síntese química, tornam-se promissores para aplicação biotecnológica.

\section{REFERÊNCIAS}

Abbas AK, Lichtman AH, Pillai S. Moléculas do complexo principal de histocompatibilidade e apresentação do antígeno aos linfócitos T. In: Imunologia Celular e Molecular. 7ed. Rio de Janeiro: Elsevier, 2011. p. 109-38.

Alberts B, Johnson A, Lewis J, Raff M, Roberts K, Walter P. Patógenos, infecção e imunidade inata. In: Biologia molecular da célula. 5ed. Porto Alegre: Artmed, 2010. p.1485-1538.

Bittner-Eddy PD, Fischer LA, Costalonga M. Identification of gingipain-specific I-Abrestricted CD4+ T cells following mucosal colonization with Porphyromonas gingivalis in C57BL/6 mice. Molecular oral microbiology 2013; 28:452-66.

Li C, Kurniyati, Hu B, Bian J, Sun J, Zhang W, Liu J, Pan Y, Lia C. Abrogation of neuraminidase reduces biofilmformation, capsule biosynthesis, and virulence of Porphyromonas gingivalis. Infection and Immunity 2012;80(1):3-13.

Lindhe J. Tratado de periodontia clínica e implantologia oral. 3ed. Rio de Janeiro: Guanabara Koogan,1999. 
Mayer MPA, Suguimoto ESA, Teixeira SRL. Microbiologia da doença periodontal. In: Spolidorio DMP, Duque C. Microbiologia e imunologia geral e odontológica. v.1. São Paulo: Artes Médicas, 2013. p.91-99.

Socransky SS, Haffajje AD. Periodontal microbial ecology. Periodontology 2000 2005; 38:135-87.

Teughels W, Quirynen M, Jakubovics N. Microbiologia periodontal. In: Newman MG, Takei H, Klokkevold PR, Carranza FA. Carranza, periodontia clínica. 11ed. Rio de Janeiro: Elsevier, 2011.p.251-94.

Vita R, Zarebski L, Greenbaum JA, Emami H, Hoof I, Salimi N, Damle R, Sette A, Peters B. The immune epitope database 2.0. Nucleic Acids Res. 2010;38(Databaseissue):D854-62.

Yang X, Yu X. An introduction to epitope prediction methods and software. Rev. Med. Virol. 2009;19(2):77-96. 